CAN CISAPRIDE OVERCOME THE EFFECTS OF OCTREOTIDE ON INTESTINAL TRANSIT, THEREBY REDUCING THE PROPORTION OF DEOXYCHOLIC ACID IN BILE AND SERUM, AND THE RISK OF GALLSTONES?

MJ Veysey, SRD Arraton, P Malcolm', A Mallet, P Jenkins ${ }^{3}$, GM Murphy, JAH Wass ${ }^{34}$, RH Dowling Gastroenterology Unit, Dept of Radiology ${ }^{1}$ and Mass Spectrometry Laboratory', UMDS of Guy's \& St Thomas' Hospitals, London and Infirmary, Oxford shown recently that, octreotide (OT) prolongs intestinal transit, and increases the factors important in the pethogenesis of OT-induced GB stones (GBS). It seemed important, therefore, to see whether the prokinetic dug cisapride, might overcome the adverse effects of $\mathrm{OT}$ on intestinal transit thereby preventing the rise in $\% \mathrm{DCA}$.

Methods: Therefore, in 8 acromegalic patients (age 22-69; 4 women) receiving long-term OT (LTOT), we used a randomised, double-blind, placebo-controlled, crossover design to study the effect of cisapride (10 $\mathrm{mg}$ qds for 2 weeks) on: (i) mouth-to-caecum transit time (MCTT) measured by the breath hydrogen technique, (ii) lange bowel transit time (LBTT) measured using marker shapes, and (iii) the \%DCA in fasting serum '(since there is an exchange, and ultimately an equilibrium between bile acids in serum and bile). We then compared these results with those obtained in 8 acromegalics (age 30-69; 3 women) untreated with OT. Results: Mean values \pm SEM

\begin{tabular}{|l|l|l|l|}
\hline & \multicolumn{3}{|c|}{ Acromegalic patients } \\
\hline & no OT & LTOT + placebo & LTOT + cisapride \\
\hline MCTT (min) & $171 \pm 14.7^{* *}$ & $268 \pm 18.3$ & $183 \pm 17.1^{* *}$ \\
\hline LBTT(h) & $39 \pm 4.9^{*}$ & $54 \pm 4.3$ & $30 \pm 4.4^{* *}$ \\
\hline \%DCA & $15 \pm 1.8^{*}$ & $24 \pm 2.9$ & $13 \pm 4.5^{*}$ \\
\hline
\end{tabular}

${ }^{*} \mathrm{p}<0.05,{ }^{* *} \mathrm{p}<0.005$ compared to LTOT + placebo. For all 3 groups, there was a significant linear relationship between LBTT and \%DCA $(\mathrm{n}=24, \mathrm{r}=0.76, \mathrm{p}<0.005)$.

Conctusions: These results clearty show that cisapride reverses the effects of OT on both small and large bowel transit, prevents the rise in \%DCA in senum, and by implication, the \%DCA in bile. If changes in intestinal transit are rate-limiting in the pathogenesis of OT-induced GBS, cisapride should prevent stone formation. the Depts of Endocrinology St Bartholomew's Hospital, London and The Raddiffe

Background: In addition to its effect on gallbladder (GB) emptying we have proportion of deoxycholic acid (\%DCA) and the cholesterol saturation of GB bile -

IS THERE A RELATIONSHIP BETWEEN ANAL MUCOSAL ELECTROSENSITIVITY AND ANAL SPHINCTER DEFECTS IN PATIENTS WITH FAECAL INCONTINENCE (FI)? Benson $\mathbf{M}^{*}$, Kumar D, Grant E, Jazrawi $R^{*}$, Lloyd R. Departments of Colorectal Surgery and Gastroenterology*, St George's Hospital, London, UK.

The aetiopathogenesis of faecal incontinence has yet to be fully elucidated. Two important factors in the maintenance of continence are the structural integrity of the internal (IAS) and external (EAS) anal sphincters and anal canal sensation. In patients with FI due to sphincter defects, it is not known whether anal canal sensation is altered and may contribute to the physiological dysfunction. The aim of this study was to study the relationship between MES and sphincter defects in patients with FI. 158 Patients (15M, 143F; median age 56ys [IQR: 34-69]) with grade III/IV were studied. All patients underwent endoanal ultrasound (EAS) using a 7.5 MHZ rotating probe and MES testing. The latter was performed by passing a direct current through a mucosal electrode placed in contact with anal mucosa and a reference electrode placed on the thigh. Sensitivity was measured in the upper, middle and lower anal canal. There was a sphincter defect in 95 patients (IAS: 10, EAS: 41 , both: 44 ). MES was impaired in 60/95 patients (IAS: 5/10, EAS 26/41, both 24/44). There was no significant difference in the occurrence of impaired MES and the site of the sphincter defect. MES was also impaired in $27 / 64$ patients with morphologically normal sphincter: this was not significantly from the defect group. In the defect group MES of the entire anal canal was impaired 34/95 (IAS:4/10, EAS: 15/41, both:15/24) and in 17/63 in patients with normal sphincters. There was no significant difference between the groups. These results show that impairment of MES is common in patients with FI. However, there is no specific association with disruption of the IAS and/or EAS. These data indicate that impairment of MES is not a direct consequence of sphincter trauma.

\section{Motility and colorectal W30-W38}

OESOPHAGEAL MOTILITY FOLLOWING CEREBROVASCULAR ACCIDENT.

PG Aithal, B Herd, AD Dwarakanath, AR Tanner.

Department of Medicine, North Tees General Hospital, Stockton on Tees, TS19 8PE.

Introduction: Assessment of swallowing in stroke patients has so far concentrated on the oropharyngeal phase. Our aim was to study oesophageal motility in selected patients during the early phase of cerebrovascular accident (CVA).

Patients and Methods: Ten patients (6 female and 4 male) aged between 48-78 years (median 67.5) with a clinical diagnosis of CVA and compatible CT scan findings were studied. Those with swallowing difficulties detected at the bedside were excluded. Oesophageal manometry was performed using solid state assembly with 3 transducers and standard techniques. Each subject was studied once between day 3-5 post CVA and during the third week. Paired ' $t$ ' test was used for statistical analysis.

Results: Mean lower oesophageal sphincter (LOS) pressure increased significantly from 13.1 (day 3-5) to $18.7 \mathrm{mmHg}$ (3rd week) $(p=0.008)$. There were increases in the duration of wet swallows from a mean of 2.7 to $3.6 \mathrm{~cm} / \mathrm{second}(p=0.002)$ and propagation of peristalsis from 1.7 to $2.6 \mathrm{~cm} / \mathrm{second}(p=0.03)$ over the study period.

Conclusions: Depressed oesophageal motor function has been demonstrated in the first 5 days after CVA, improvement has been shown three weeks later. Low LOS pressures and impaired peristaltic function immediately following a CVA may predispose to aspiration, by enhancing reflux and depressing oesophageal clearance. Improving oesophageal function over the next 3 weeks correlates with decreasing risk of aspiration demonstrated in other studies.
TERMINÁL ILEAL EMPTYING: SLOWER FOR SOLIDS THAN LIQUIDS, AND INHIBITED BY A SECOND LIQUID MEAL.

Hebden JM 1 , Blackshaw PE², Perkins AC ${ }^{2}$, D'Amato ${ }^{3}$, Spiller $\mathrm{RC}^{1}$. Division of Gastroenterology ${ }^{1}$ and Medical Physics ${ }^{2}$ University Hospital Nottingham, UK, and Rotta Research Laboratorium ${ }^{3}$, Monza, Italy.

Although ileo-colonic transfer of solids is known to occur episodically, little is known about the control mechanism. We hypothesised that transfer of a solid meal into the colon would be augmented by ingestion of a subsequent liquid meal. Methods: 12 volunteers participated in a 2 part study. In part 1 , fasted subjects ingested $5 \mathrm{MBq}$ Tc $99 \mathrm{~m}$-labelled resin baked into a pancake $(400 \mathrm{kcal})$ containing $15 \mathrm{gms}$ of bran. Serial images were obtained to determine the T50 gastric emptying (GE) and T50 colonic arrival of the meal until the end of the study at $11 \mathrm{~h}$, with fluids only allowed. In part 2 an identical protocol was followed with an additional second $540 \mathrm{kcal}$ liquid meal $(400 \mathrm{kcal}$ Clinifeed drink and 2 digestive biscuits) labelled with water soluble In[111]-DTPA, and given $3 \mathrm{~h}$ after the pancake. Results: (meantSEM). GE of the pancake was similar in parts 1 and 2 , T50 being $115 \pm 14$ and $113 \pm 11$ mins (NS). At the end of the study it was not possible to determine the T50 colonic arrival of the solid meal, as $<50 \%$ of Tc $99 \mathrm{~m}$ label lay in the colon both in parts 1 and 2. A significantly smaller proportion of Tc99m label lay in the colon (11h post ingestion) in part 2 compared to part 1 $(5 \pm 3 \%$ v $18 \pm 4 \%, p<0.05)$. In addition, a much higher proportion

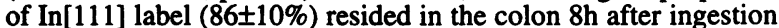
Small bowel transit was significantly faster for the liquid compared to solid meal $(3.6 \pm 0.4 \mathrm{v}>9.1 \mathrm{~h}, \mathrm{p}<0.01)$, resulting in the liquid meal overtaking the solid meal. Conclusions: 1 . Feeding the liquid meal slowed terminal ileal transit of the first meal implying that a fasting motility pattern is more effective in clearing the terminal ileum of solid residue. 2. Surprisingly, the liquid phase marker of the second meal overtook the solid phase of the first meal, implying a sieving effect of the terminal ileum with selective retention of solid residue. 
FATTY ACID INHIBITION OF ANTRAL CONTRACTILITY IS MEDIATED BY CCK ACTING AT CCK-A RECEPTORS

MG Luca *, JT McLaughlin, A Jones, $H$ Mamtora**, MD'Amato***, GJ Dockray\#, DG Thompson. Department of Medicine and "**Radiology, Hope Hospital, Salford, M6 8HD, *Padua, Italy, **Rotta Research Laboratorium, Monza, Italy, and \#Physiology, Liverpool University, UK. Supported by BBSRC.

Background: Nonhydrolysed fat inhibits fed state antral contractility. It is not known whether this is due to direct (neural) contractility. It is not known whether this is due to direct (neural)
or indirect (endocrine, eg CCK) effects of fat on the stomach. Since fatty acids (FA) of $\mathrm{C} 12$ acyl chain and longer both delay gastric emptying and release CCK, this peptide has been suggested as a candidate mediator for fat induced changes in antral motility. Aim: to establish the role of CCK in FA inhibition of antra contractility.

Methods: Meals: Vehicle solution (V) of phosphate buffered saline $+1.5 \% \mathrm{v} / \mathrm{v}$ emulsifier (Tween $80 \mathrm{pH} 7.4$, $350 \mathrm{mOm} / \mathrm{kg}$ ) was used either alone as (control meal) or with FA (C10 or C12) dispersed as a $0.10 \mathrm{M}$ emulsion. Antral fed state activity was stimulated by $360 \mathrm{ml}$ low fat chicken soup (CS, 200kCal). Protocol I: 8 healthy volunteers underwent 22 studies on separate days. Baseline fasted antral ultrasound was performed, on separate days. Baseline fasted antral ultrasound was performed,
then $100 \mathrm{ml}$ V or FA emulsion was administered by orogastric tube; 15 minutes later the subject consumed soup per os. Antral ultrasound was continued for one hour. The excursion ratio (ER) of antral contractions was calculated as relaxed minus contracted antral circumference divided by relaxed circumference. Plasma samples were taken for CCK radioimmunoassay before and $15 \mathrm{~min}$ after FA. Protocol 2: The experiment was repeated following C12 after FA. Protocol 2: The experiment was repeated following C12 $30 \mathrm{mg} / \mathrm{kg} / \mathrm{h} 10 \mathrm{mins}$ then $10 \mathrm{mg} / \mathrm{kg} / \mathrm{hr}$ ) Effective CCK-A blockade was demonstrated by failure of gallbladder contraction. Results * $p<0.05$ vs vehicle or C10; \# $p<0.05$ vs fasting (mean \pm SEM) vehicle C10 C12 C12/LOX

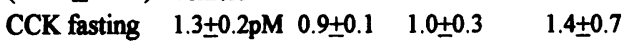
$\begin{array}{lllll}\text { CCK } 15 \min & 2.0 \pm 0.6 & 2.0+0.7 & 4.0 \pm 0.7^{*}, \# & 8.6 \pm 1.4^{*}, \#\end{array}$ ER $0.32 \pm 0.04 \quad 0.3 \pm 0.03 \quad 0.17 \pm 0.06^{*} \quad 0.30 \pm 0.02$

Conclusions: antral motility is inhibited by $\mathrm{C} 12$ but not C10 fatty acid. This inhibition is mediated by CCK acting at CCK-A receptors.

\section{DEMONSTRATION THAT LACTULOSE INCREASES} INTRACOLONIC WATER CONTENT, DISPERSION, AND DRUG ABSORPTION BY COMBINED COLONIC ECHOPLANAR IMAGING (EPI) AND SCINTIGRAPHY.

Hebden JM ${ }^{1}$, Gilchrist $\mathrm{PJ}^{4}$, Perkins $\mathrm{AC}^{2}$, Frier $\mathrm{M}^{2}$, Boulby $\mathrm{P}^{3}$, Gowland $\mathrm{P}^{3}$, Wilson $\mathrm{CG}^{4}$, Spiller RC ${ }^{1}$. Departments of Gastroenterology ${ }^{1}$, Medical Physics ${ }^{2} \&$ MR Institute ${ }^{3}$, University Hospital, Nottingham, and Dept of Pharmaceutical Sciences ${ }^{4}$, University of Strathclyde 3 .

We have previously demonstrated enhanced absorption from the proximal $\mathrm{v}$ distal colon. We postulated that this was due to increased proximal water content augmenting absorption by increasing mucosal contact. The aim of this study was to increase or decrease intracolonic water content using lactulose or codeine respectively, and to observe the effect on absorption. Methods. 16 volunteers were randomised to a 3 way 5 day crossover study and were treated with lactulose $20 \mathrm{mls}$ tds, codeine $30 \mathrm{mg}$ qds, or control diet alone. EPI on day 3 allowed assessment of colonic water (T1 values). Stools were also freeze-dried to assess water content. Indium labelled amberlite resin and quinine were targeted to the distal gut using a timed release delivery system. Serial scintigraphy determined release position, ascending colon transit time (ACCT), and dispersion at $3 \mathrm{~h}$ (avge number of colonic regions of interest containing $>10 \%$ of dose). Absorption was measured on a $20 \mathrm{~h}$ urine collection. Results. [mean \pm SEM] Lactulose treatment caused more extensive dispersion $[3.4 \pm 0.3 \mathrm{v}$ $1.6 \pm 0.2, p=0.04]$, an increase in free intracolonic water [T1 $69 \pm 9 \mathrm{~ms} v 49 \pm 4, p=0.03$ one-tailed] and stool water $[75 \pm 2 \% \mathrm{v}$ $61 \pm 2 \%, p<0.001]$, and a shortened ACTT $[3.7 \pm 0.8 \times 8.9 \pm 1.8 \mathrm{~h}$, $\mathrm{p}<0.01$ ] compared to codeine. Position of release of drug was similar in all 3 treatment groups. Absorption was increased by lactulose $v$ control (median $4.25 \%$ v $2.60 \%, p=0.02$ ) Conclusion. Lactulose enhances drug absorption. We speculate that this is due to increased colonic water which lowers luminal viscosity, facilitating drug diffusion from lumen to mucosa.
OCTREOTIDE PROLONGS LARGE BOWEL TRANSIT, THEREBY INCREASING THE PROPORTION OF DEOXYCHOLIC ACID IN BILE AND SERUM AND THE RISK OF GALLSTONES.

MJ Veysey, SRD Arraton, A Mallet', P' Jenkins', GM Murphy, JAH Wass ${ }^{23}$, RH Dowling. Gastroenterology Unit and Mass Spectrometry Laboratory', UMDS of Guy's and St Thomas' Hospitals, London and the Depts of Endocrinology St Bartholomew's Hospital, London ${ }^{2}$ and The Raddliffe Infirmary, Oxford ${ }^{3}$.

Background: Long-term (1-2 yr) octreotide (OT) treatment induces the formation of gallbladder stones (GBS) in up to $50 \%$ of acromegalic patients not only by impairing meal-stimulated gallbladder emptying but also by increasing the proportion of deoxycholic acid (\%DCA) and the cholesterol saturation of gallbladder bile. Prolongation of intestinal transit has been implicated in this increase in the \%DCA but our previous unpaired studies failed to show a significant effect of OT" on large bowel transit - important since the colon is the site of DCA formation and absorption.

Methods: Therefore, in 8 acromegalic patients (age range 22-69; 4 women), we used a radio-opaque marker shape technique to measure large bowel transit time (LBTT) before and during long-term ( $>3$ months) OT treatment (100$200 \mu \mathrm{g}$ tds by sc injection). Furthermore, since there is an exchange, and ultimately an equilibrium, between bile acids in serum and bile, we also measured the proportions of cholic, chenodeoxycholic, deoxycholic and ursodeoxycholic acids, in fasting serum from 6 of these patients using gas chromatography-mass spectrometry.

Results: The mean LBTT increased from 42 SEM 4.3h before to $55 \pm 5$. $1 \mathrm{~h}$ during OT treatment $(p<0.0001)$ and the mean \%DCA increased from $15 \pm 2.5 \%$ to $28 \pm 4.7 \%(p<0.05)$. There was also a significant linear relationship between LBTT and \%DCA $(r=0.87, p<0.0005)$. There were no significant correlations between LBTT and the proportions of the other serum bile acids.

Conclusions: These paired studies have shown that long-term OT prolongs LBTT and leads to an associated increase in the \%DCA in serum, and by implication in bile, with an attendant increase in the risk of gallstone formation.
ENDOANAL ULTRASONOGRAPHY: CAN IT DETECT RECTOCELES?

Benson $\mathrm{M}^{*}$, Kumar D, Grant E. Department of Coloproctology and Gastroenterology*, St George's Hospital, Tooting, London, UK.

Endoanal ultrasonography is commonly used to detect sphincter defects in patients with faecal incontinence. A rectocele is a prolapse of the rectum into the vagina and is commonly diagnosed on barium proctography or isotope defaecography. In addition to being invasive, these techniques involve administration of significant amounts of radiation. The aim of this study was to assess the efficacy of endoanal ultrasonography in diagnosing rectoceles.

We performed endoanal ultrasound (EUA) on 111 patients with a clinical diagnosis of rectocele. All patients had isotope defaecography to quantify rectal and rectocele emptying. EUA was performed using a rotating $7.5 \mathrm{MHz}$ ultrasound probe with the patient in the left lateral position. EUA diagnosed a rectocele in 88 of 111 patients $(80 \%)$. 68 of the 88 patients diagnosed to have a rectocele on EUA had a significant rectocele ( $>15 \%$ isotope retention). More importantly, only 6 of $23(25 \%)$ whose rectocele was not seen on EUA had a significant rectocele. These results were confirmed by the results of isotope defaecography. EUA was also performed in 22 patients who had undergone rectocele repair. In none of these patients a rectocele was seen on EUA. This was confirmed on subsequent isotope defaecography.

This may prove to be a non-invasive way of selecting patients with rectoceles for further investigation. 
W37

\section{ANOPLASTY - AN ALTERNATIVE TREATMENT FOR CHRONIC} FISSURE IN ANO

A.G. Radcliffe, P.N. Haray, P.K. Dixon. Llandough Hospital, Penarth, Cardiff.

Introduction: Anoplasty has previously been used to correct anal stenosis associated with a fissure in ano. The procedure has been extended to avoid repeated anal stretches or sphincterotomy and in other circumstances where there is a danger of incontinence.

Aims: 10 patients with chronic fissure in ano have been treated using the technique of anoplasty; these being operated under the care of one clinician.

Patients and Methods: The age of the patients ranged from 25 to 64 (mean-45.7 years), 7 male and 3 female. All the patients had chronic fissure in ano with a mean duration of symptoms of 14 months (range 6 months to 5 years). They had all had a supervised trial of conservative management. Eight of the 10 patients had had previous surgery (6 -anal stretch and 3 -internal sphincterotomy). Two patients had anal stenosis. The site of the fissure was predominantly posterior.

Operative technique: The patients were operated in the prone 'jack-knife' position. The site of the chronic/recurrent fissure was superficially excised. A flap of healthy perianal skin was raised and mobilised and advanced into the anal canal and sutured in place. Seven of the 10 patients had a diamond shaped flap while the 3 had a V-Y advancement. Patients were discharged from the hospital on an average in 3.8 days (range 2 to 9 days).

Results: 9 of the 10 patients in this series had symptomatic relief and complete healing of the fissure on follow up examination. The follow up period was between 2 and 10 months (mean 5 months). There was one recurrence treated by sphincterotomy. Morbidity included minimal wound infection in 2 patients and post operative urinary retention in one patient.

Conclusion: The technique of anoplasty appears to be satisfactory in the treatment of recurrent chronic anal fissures avoiding iatrogenic damage to the sphincter mechanism. We feel that it may well have a role to play as the primary surgical procedure of choice in patients who are not relieved by conservative management and where there is a danger of precipitating incontinence.

\section{Liver (clinical), and paediatrics W39-W46} W39

A COMPARISON OF WILSON'S DISEASE IN BRITAIN \& INDIA ${ }^{1}$ Balac $P,{ }^{3}$ Bavdekar A, ${ }^{2}$ Curtis $D,{ }^{3}$ Pandit A, ${ }^{2}$ Quarrell O, ${ }^{1}$ Tanner $S$. ${ }^{1}$ Dept of Paediatrics, ${ }^{2}$ Centre for Human Genetics, Children's Hospital, Sheffield; ${ }^{3}$ King Edward Memorial Hospital, Pune, India

Wilson's disease (WD) has a worldwide incidence of $1: 35,000$ to $1: 100,000$, variably presenting as either hepatic or neurological. We compared a cohort of WD patients from Britain and India by clinical presentation, linked markers and mutations. There were 25 Caucasian British families and 43 Indian families from the Pune region. DNA was obtained by consent from parents, affected children and siblings.

Hepatic presentation of the index case occurred in $16(64 \%)$ of the British families and $28(65 \%)$ of the Indian families. Particular features of Indian hepatic cases were early age of onset (below the age of 7 in at least 6 families), accompanying neurological symptoms (in 6 families) and Kayser-Fleischer rings, features not seen in British cases.

Haplotype analysis was performed using three linked microsatellite markers D13S314, D13S301 and D13S296 (1). Common mutation screening was performed using PCR and restriction enzyme digest (2).

In British families, haplotype analysis suggested most patients were compound heterozygotes. 20 Indian haplotypes were homozygous, suggesting identical mutations. There was no common British WD haplotype, but a common haplotype (3-5-4) was on 14\% of Indian WD alleles. In British families, the common mutation $\mathrm{H} 1069 \mathrm{Q}$ was on 5 alleles (10\%) and G1266R on 3 alleles (6\%). These mutations were not found in any Indian case. I1 102T was homozygous in 2 Indian patients.

In 27 Indian families, 45 siblings were investigated for carrier status using the linked markers. 15 were normal, 27 were carriers and 3 were found to have WD. In two cases the original diagnosis was reversed.

In conclusion, WD should be suspected earlier than 7 years of age, especially in immigrant Asian families who may be consanguineous and have a much higher carrier rate of WD mutations. DNA analysis using linked markers can offer early diagnosis where there is already an affected WD child. WD haplotypes offer clues to identifying mutations. (1) Thomas et al (1995) Am J Hum Genet 56: 1315-1319.

(2) Morris et al (1995) Gut 37: A20.
DISTRIBUTION OF INTERSTITIAL CELLS OF CAJAL (ICC) IN THE HUMAN ANORECTUM, A COMPARISON WTTH THE HUMAN COLON.

Hagger R. Finlayson C.* Jeffrey I.* and Kumar D. Dept. of Surgery and Dept. of Histopathology. * St. George's Hospital, London, United Kingdom

Aim: The interstitial cells of Cajal have a proposed role in the control of gut motility. The aim of this study was to establish the normal pattern of distribution of ICC in the human anorectum and compare it to the human colon.

Methods: ICC express the proto-oncogene c-kit, a cell surface tyrosine kinase receptor. ICC were identified in the anorectum and colon by immunohistochemical staining, using a rabbit polyclonal anti-c-kit antibody (Oncogene Science). Normal anorectal or colonic tissue was defined as non-involved tissue obtained at surgical resection for a non-obstructing carcinoma of the rectum or colon. 40 colonic and 25 anorectal tissue blocks were studied.

Results: In the rectum, the greatest density of ICC was observed in the muscular layers. In the longitudinal and circular muscle layers ICC were seen in the muscle bulk and in association with penetrating blood vessels. The ICC were mainly in parallel orientation with the muscle fibres, but dendritic processes did ramify between the muscle fibres more frequently than that observed in the colon. In the intermuscular plane ICC encased the myenteric plexus, but less densely than in the colon. At the inner margin of the circular muscle, ICC lined the muscle layer and were also found in association with neural elements of the submucous plexus. Within the internal anal sphincter ICC were infrequent, being sparsely scattered among the muscle fibres.

Conclusion: ICC are present in the human anorectum, their pattern of distribution differs to that seen in the colon, the highest density of ICC being in the muscular layers rather than in the intermuscular plane. In the rectum the distribution of ICC would suggest a role in the generation and co-ordination of muscular activity.
HYPERFERRITINAEMIA WITH CATARACTS: A NEW HEREDITARY CONDITION.

J O Lindsay, A Mumford, M Hagan, U Hegde, R Hawkins, and J Arnold. Dept. Medicine, Ealing Hospital, Southall, UB1 3HW.

Ferritin, the main intracellular iron storage protein, consists of two chains; a heavy $(21 \mathrm{Kda})$, and a light $(19 \mathrm{Kda})$. Ferritin synthesis is controlled at the level of mRNA translation by an iron responsive mechanism, and reflects the intracellular iron concentration. This control process depends on a highly conserved motif at the 5' non coding region of the ferritin mRNA. The only familial condition associated with hyperferritinaemia is genetic haemochromatosis

We present the first kindred in the U.K. in which there is a familial association between early onset cataracts and hyperferritinaemia in the absence of an acute phase response The ferritin level in affected family members is independent of iron status. 13 members of a family were investigated after the detection of hyperferritinaemia in the proband. 6 members from 3 generations had ferritin levels in excess of 800 $\mathrm{g} /$, despite normal iron and transferrin saturations, and plasma viscosities. A liver biopsy from one patient demonstrated no excess stainable iron. Phlebotomy resulting in biochemical iron deficiency had no effect on ferritin levels. All 6 with raised ferritin levels had sutural opacities on slit lamp examination of their lens'. The other family members had a normal ophthalmic examination. Direct cycle sequencing of PCR-amplified DNA from the 5 ' end of the L-ferritin gene on chromosome 19 revealed a $T$ to $C$ mutation in the iron responsive element that was only present in affected family members.

This represents the first described mutation in an Iron Responsive Element in the U.K.. The description of this new autosomal dominant genetic condition has wide implications for the use of ferritin as a marker of iron overload in the screening and treatment of patients with haemochromatosis. 